\title{
XRD and CO2 adsorption studies of modified silica gel with octadecylamine
}

\begin{abstract}
Porous surface of silica gel (SG) have been modified with long and straight chain fatty amine compounds (octadecylamine, ODA) via wet impregnation process. Initially, heat treatment with various temperature which are $100{ }^{\circ} \mathrm{C}, 200{ }^{\circ} \mathrm{C}, 400{ }^{\circ} \mathrm{C}$ and $600{ }^{\circ} \mathrm{C}$ was done to the SG before continuing with impregnation process. Characterizations by XRD of the treated samples were showed no significant difference in each diffractogram. The best temperature for heat treatment was $600{ }^{\circ} \mathrm{C}$ (SG600) and it was referred to the ability of the SG600 type adsorbents in adsorbing $\mathrm{CO} 2$ resulted from adsorption desorption isotherm of $\mathrm{CO} 2$. The 5 and $35 \mathrm{wt} \%$ of ODA supported on the SG600 was further characterized using XRD analysis which displayed the increasing intensity of crystalline ODA with higher percent amine loaded and shifting of the several crystalline peaks of ODA verified the interaction of SG600-ODA. These further strengthen the dispersion of ODA on the surface of SG600.
\end{abstract}

Keyword: $\quad \mathrm{CO} 2$ capture; Modified silica gel; Octadecylamine impregnation 